\title{
Adapted Physical Activity Design Projects: A Collaboration Between Kinesi- ology and Engineering
}

\section{Dr. Brian P. Self, California Polytechnic State University}

Dr Self has taught in the Mechanical Engineering Department at Cal Poly, San Luis Obispo since 2006. Prior to that, he worked in the Air Force Research Laboratories before teaching at the U.S. Air Force Academy for seven years. During the 2011-2012 academic year he participated in a professor exchange, teaching at the Munich University of Applied Sciences. His engineering education activities include collaborating on the Dynamics Concept Inventory, developing model-eliciting activities in mechanical engineering courses, inquiry-based learning in mechanics, and design projects to help promote adapted physical activities. Other professional interests include aviation physiology and biomechanics. Dr Self obtained his B.S. and M.S. degrees in Engineering Mechanics from Virginia Tech, and his Ph.D. in Bioengineering from the University of Utah.

\section{Dr. James M Widmann, California Polytechnic State University}

Jim Widmann is a Professor of Mechanical Engineering at California Polytechnic State University, San Luis Obispo. He received his Ph.D. in 1994 from Stanford University. Currently he teaches mechanics and design courses. He conducts research in the areas of machine design, fluid power control and engineering education. He is a past Chair of the ASEE-DEED Division and a U.S. Fulbright Scholar.

\section{Dr. Lynne A Slivovsky, California Polytechnic State University \\ Prof. J.Kevin Taylor \\ Dr. David W. Hey, California Polytechnic State University}

Dr. David Hey received his BS and MS from Wisconsin-La Crosse and PhD from Southern Illinois University where he studied health education and focused his research on qualitative measures (viz., content analysis, communication, and ethnography) involving obesity in kids. Upon arriving at Cal Poly and the obesity research center "STRIDE" (Science through Translational Research in Diet and Exercise, a unique opportunity arose to expand and conduct focus groups to explore the barriers people were experiencing to exercise and eating healthfully. For this particular research study David was responsible for collecting and analyzing the engineering student's focus group data on their capstone projects, specifically in learning design. He credits the cross collaboration between kinesiology and engineering as a most satisfying and rewarding experience. 


\title{
Adapted Physical Activity Design Projects: A Collaboration Between Kinesiology and Engineering
}

\begin{abstract}
Capstone design projects have been an important culminating experience for engineers across the country. At Cal Poly, a subset of our projects have focused on adapted physical activity. Engineering teams have built cross-country sit skis, "standing" wheelchairs, Wii adapters for users with limited mobility, and devices that allow people with disabilities to play Frisbee, golf, darts, bocce ball, and baseball. Teams are often from multiple engineering majors, including mechanical, computer, biomedical, materials, and industrial engineering. What makes our program truly unique, however, is how we have integrated students from the Kinesiology Department in our senior design experience.
\end{abstract}

Students within the Kinesiology Department take a course in their junior year on adapted physical activity, and volunteer in the department's Friday Club. On Friday mornings, athletes from Special Olympics participate in a number of different sporting activities with the help of the kinesiology students. In their senior year these students can take a course to serve as a liaison and team member with the engineering design teams. The students meet with a kinesiology advisor each week to discuss progress with their teams, discuss different user requirements for the adapted physical activity devices, and brainstorm about potential design improvements. They meet with the senior engineering teams, with the users when possible, and often research different aspects of the design (e.g., maximum forces that someone with a mobility impairment can produce).

Although the projects have been largely successful, we have had some difficulties fully integrating the kinesiology students within the teams. The faculty advisors have largely allowed the engineering and kinesiology students to define their own roles, but from different focus group results it appears that we need to provide more guidance. Additionally, this year we will have the kinesiology students attend the critical laboratory meetings when the engineers brainstorm different designs and define design specifications.

\section{Background}

\section{Adapted Physical Activity}

Clearly physical activity is profoundly beneficial in a myriad of ways, but for people with disabilities the benefits are potentially even more profound. In addition to the obvious cardiorespiratory endurance and weight control benefits, physical activity has a number of other socialpsychological benefits. Many of these widely acknowledged benefits of physical activity directly counter the impact of disability. For example, people with disabilities are predisposed to having low self-concept, poor self-image and low self-esteem all of which may be countered through physical activity ${ }^{6}$. 
Many people with disabilities live in some degree of social isolation and develop strong feelings of isolation and exclusion, which can be reduced by facilitating their inclusion in physical recreation ${ }^{5}$. Participation in physical recreation has the potential to reduce isolation and foster new friendships, which in turn can help, maintain the individual's participation. Extending an individual's social support network of friends and family is critical to promoting long-term inclusion in adapted physical activity settings ${ }^{1}$.

Participants in adapted physical activity settings report that they are often no longer viewed as being disabled while they are participating in sport $^{3}$. Adapted physical activity affords people the opportunity to increase their self-awareness, to have pride in their accomplishments and find self-exploration through physical activity. Participation in physical activity helps others to view individuals with disability differently as they see them actively engaged "outside of the illness metaphor" (ref [3], p. 392).

\section{Kinesiology}

In order to help address these issues, the Kinesiology Department at Cal Poly conducts has a course, Kine 307 Adapted Physical Activity, as well as a series of programs (see Figure 1) to help these athletes achieve their goals. As part of this program, the Kinesiology Department has made kayaking in a local bay accessible to over 40 community participants who are diagnosed with differing levels of spinal cord injuries. Similar benefits have been obtained through the EyeCycle program, where people who are blind or visually impaired ride tandem bicycles. Kinesiology students take the "captain's" position while participants sit in the "stoker" position. A third part of the Kinesiology Adapted Activity Program is the Friday Club. This is a Special Olympics program that brings people with developmental disabilities to the Cal Poly campus to learn a variety of sports skills. Cal Poly students help instructors teach soccer in the fall, basketball in the winter, and track and field in the spring.

Dr Taylor in the Kinesiology Department soon realized that the equipment available for many of the adapted physical activities was inadequate. He recognized that the Engineering Departments at Cal Poly have a strong capstone design sequence, and initiated a series of collaborations that eventually led to an NSF grant, "Access by Design: Capstone Projects to Promote Adapted Physical Activity." 


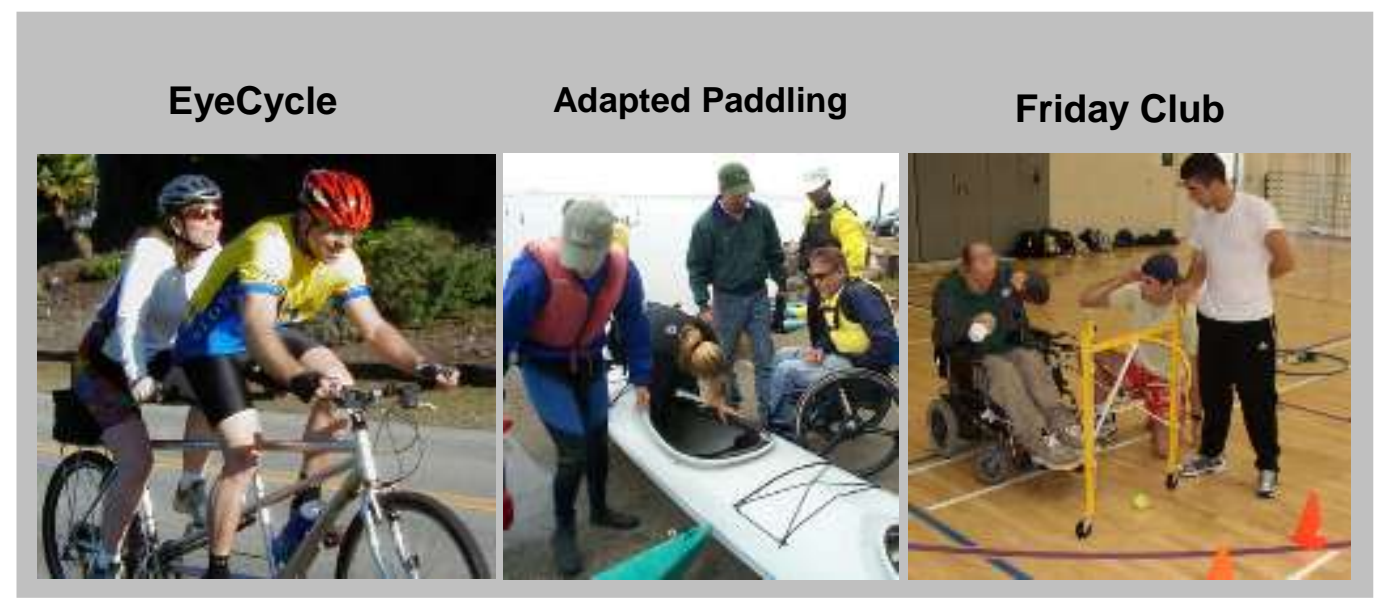

Figure 1. Components of the Adapted Physical Activity Program.

\section{Senior Design in Engineering}

Capstone experiences typically provide teams of students with complex real-world design projects. In both $\mathrm{CPE}$ and $\mathrm{ME}$, teams of three to six students work on large design projects during a two or three quarter design class. While most projects at Cal Poly are disciplinespecific, there continues to be an increase in multidisciplinary project teams formed across the different majors.

Students deal with a real customer and are expected to develop a set of core technical competencies related to their project. To this end, they synthesize material from prior coursework and new research related to their projects. In most cases, this is a student's first significant open-ended design experience in a team environment. While many students encounter growing pains during the design class, later reflection indicates a sense of pride in the personal development that occurs.

As expected, a focus of the class is on the end product and the deliverables to the customer. However, the process the students follow is equally important as we are teaching our students fundamental skills, such as critical thinking and lifelong learning, which will be necessary for them to be successful in today's world. To nurture both, a number of activities and class milestones have been developed to enhance team building, the design process, concept selection ${ }^{9}$, incorporation of the end-user into the design ${ }^{2}$, and communication.

There are approximately 100 senior design projects in our programs each year at Cal Poly. The majority of these are industry projects, ranging from software systems to large telescope mounts. Over the past five years, there have been at least 10 projects each year involving adapted physical activity. These have been conducted primarily in mechanical and computer engineering, but have also involved students from biomedical, materials, and general engineering. Several projects have also included multidisciplinary engineering teams. 


\section{Collaboration Between Kinesiology and Engineering Teams}

Students who show particular aptitude in the Kine 307 lab are steered towards collaborating with the engineering teams for their senior project. Typically, one or two Kinesiology students were assigned to 2-3 engineering teams. These students enrich the collaborative projects in a variety of ways. At the beginning of the project, the students prepare and present a Disabilities Etiquette workshop to help the engineering students understand more about the population with which they will be working.

In the initial design phase, they help to generate ideas and serve as a critical sounding board. Through their work in the Adapted Physical Activity programs, Kinesiology students serve to connect engineering students with the people who will ultimately use the equipment being designed. As the design phase of collaborative projects nears completion, the Kinesiology students focus their attention on the long-term use of the equipment. In order to ensure that the projects are ultimately used and enjoyed safely, Kinesiology students also help to write guidelines and instructions for playing with and using the equipment produced.

Evaluation of Kinesiology/Engineering Collaboration

To date, most of our assessment has involved the engineering teams, including their motivation, learning design, and overall attitudes towards the adapted physical activity projects ${ }^{4,10-12}$. Recently we have held a number of different focus groups, which have primarily included the engineering students. Additionally, we have performed one focus group with kinesiology students. The focus group discussion followed a protocol based on a semi-structured interview guide, which was developed in accordance with established guidelines ${ }^{7,8}$.

\section{Engineering Student Focus Groups}

Engineering students enroll in the senior project course and are assigned to one of seventeen adapted design projects were purposefully selected $(n=61)$. All projects had the intent of promoting inclusion for people with disabilities in a specific physical activity. Projects included: a Hand and Foot Powered Cycle; a golf attachment for a Universal Play Frame; an inclusive court game called Foam Wars; an adaption to a Nintendo Wii system, Wii-B-Fit; a mobile standing frame called a Strider for a youth; a Sit Ski; an adapted Paddling Launch Vehicle (APLV); and a second iteration of the hand and foot powered cycle, named "Quadricycle"; second iteration of Foam Wars II; UPF VI; Strider II for an adult; a system that allows low vision people to run "Untethered Running; second iteration of Wii-B-Fit II; Adapted Darts; Bocci; a device to allow people to bowl named "Rock-N-Bowl"; and a wheel chair that does wheelies aptly named "Pop a Wheelie" (Table 1). Criterion sampling was used (i.e., assigned individuals to a given project were selected to attend a one hour team focus group at the end of their 9 month capstone project). Seventeen focus groups were conducted from spring 2009 to spring 2012 with 61 participants (52 male / 9 female). 
TABLE I

DESIGN PROJECT AND STUDENT ENGINEERS

\begin{tabular}{|c|c|c|c|c|c|c|}
\hline Project No. & Project Title & Year & Male & Female & $1^{\text {st }}$ Choice? & Client Contact \\
\hline 1 & Hand Foot Powered Cycle & 2009 & 4 & 0 & 2 & High \\
\hline 2 & Universal Play Frame Golf & 2009 & 1 & $2 \dagger$ & 2 & Medium-High \\
\hline 3 & Foam Wars & 2009 & 3 & 0 & 1 & Low \\
\hline 4 & Wii-B-Fit & 2009 & 3 & 1 & 4 & Medium-High \\
\hline 5 & Strider (youth) & 2009 & 3 & 0 & 1 & High \\
\hline 6 & Sit Ski & 2010 & 3 & 0 & 1 & Low-Medium \\
\hline 7 & APLV & 2010 & $3 *$ & 1 & 2 & High \\
\hline 8 & Quadricycle & 2010 & 3 & 1 & 4 & High \\
\hline 9 & Foam Wars II & 2010 & $3^{*}$ & 1 & 3 & Medium \\
\hline 10 & UPF VI & 2010 & 3 & 1 & 0 & Medium-High \\
\hline 11 & Strider II (adult) & 2011 & 3 & 1 & 2 & High \\
\hline 12 & Untethered Running & 2011 & $5^{*}$ & 0 & 3 & Medium \\
\hline 13 & Wii-B-Fit II & 2011 & 4 & 0 & 2 & Low-Medium \\
\hline 14 & Adapted Darts & 2011 & 2 & 1 & 3 & Medium-High \\
\hline 15 & Bocci & 2011 & 3 & 0 & 1 & Medium \\
\hline 16 & Rock-N-Bowl & 2011 & 3 & 0 & 1 & Low-Medium \\
\hline 17 & Pop a Wheelie & 2011 & $2 *$ & $1 \dagger$ & 1 & Medium \\
\hline Totals & & & 52 & 9 & 33 & NA \\
\hline
\end{tabular}

Note: Students who reported 'extensive prior experience' to people with disabilities $(*=1 \mathrm{male} / \uparrow=1$ female $)$

Comments that are specifically related to the Kinesiology student collaboration are provided below based on three themes: (a) the Etiquette Presentation (b) Planning and Scheduling, and (c) Improving Future Projects: Communication between the Disciplines. Names have been changed, but are consistent with the gender of the engineering student.

\section{Theme 1. Etiquette presentation}

Prior to the project, more females $(22.2 \%)$ had 'extensive' experience working with people with disabilities than males (13\%); however overall the vast majority of the participants had 'no' prior experience with people with disabilities (males $65 \%$ / females $33 \%$ ); with males $(26 \%$ ) and females $(33 \%)$ having reported 'limited' experience. Students commented on

Wii-B-Fit (2009)

Wally: [On importance of workshop and benefit gained]: "Yeah greatly... I guess it kind of changed our perspective in a way. Up until now I never knew how I should interact with people with disabilities."

Wii-B-Fit (2009)

Wally: "I think through this project and the disability workshop that some of the Kinesiology students put on helped me to be more comfortable with my interaction."

Wii B Fit II (2011)

Nathan: "I learned a lot about working with disabled people have been in contact with someone with quadriplegia before the presentation being able to talk to them and being able to see what bothers them and what they want, you know? As opposed to what we think they want, it was a lot different when we spoke to the client."

Pop a Wheelie (2011)

Forrest: "I would also say meeting the sponsors that are just there. Open view of how their abilities and rather than their disabilities. They don't focus on their restrictions but 
on how they can expand what they can do and having our product being a part of that. That was really inspiring."

\section{Theme 2. Planning and Scheduling}

Students identify basic needs (purpose and/or reason for the design), define what the problem really is, identify constraints and then students look to improve a current design by looking at the strengths and weaknesses of the current design. Communication is an important issue to address early on in the project. The potential for project difficulties, barriers and delays caused by poor communication was experienced by some.

Wii-B-Fit (2009)

Margie: "I'd think the Kinesiology student working with us has been doing a great job especially the last few weeks... but early on in the quarter it would be cool to get more involvement and more help scheduling things."

APLV (2010)

Carlos: "We had really good Kinesiology students we were working with. They were on top of things. The communication doesn't need to be improved."

Strider (2009)

Aidro: "None of us had manufacturing experience and things took longer than expected. Towards the end we felt like they (Kinesiology students) were being pushy and the initial deadlines flew by."

\section{Theme 3. Improving Future Projects: Communication between the Disciplines}

Communication takes many forms (meetings, phone calls, emails and conversations etc.), and can be a major barrier for any profession, let alone engineering. Too many people assume that communication happens as long as people use accurate words. When different disciplines are working together, wording is crucial for understanding as communication hasn't happened unless the receiver can 'internalize' the message. Words, tone, and body-language matter, but the literal, factual words are only part of successful communication. Introversion or extroverted personalities can also play a significant role. The key is to address difficult issues openly, be timely (not speaking is communicating), and allow for patience. On multidisciplinary work and collaboration between Engineering and Kinesiology students:

Quadricycle (2010)

Julian: "We didn't realize they could become involved in a building or designing kind of aspect as much, and so we would say emphasis that is in it's a team. The Kinesiology students can, particularly in the design. We didn't realize maybe it seems obvious but we didn't really take advantage of the knowledge our teammates had till the very end."

\section{UPF Golf (2009)}

David: "I think it was unclear from the beginning what the role of the Kinesiology student was. We had to meet with them all the time but what were they actually doing? So maybe a little more background into that; would help the project in regards to the fluidity and everything." 
UPF Golf (2009)

Gina: "They (Kinesiology students) kind of validated our design as we went along and said 'hey, it's going to be good' or 'No, why don't you use this?' Sometimes it's kind of nice having an outsider's input rather than just engineering the entire time. They (Kinesiology students) definitely had more exposure to the users than we had. They kind of kept reminding us of things we needed to keep in consideration."

\section{UPF Golf (2009)}

"We all were under the impression (in the beginning) that we were to make one UPF Golf device and it turns out that the sponsors were hoping for two or three for that price. We received full funding but we all were hoping we weren't disappointing our sponsor by delivering one. That kind of miscommunication was kind of bad too, I guess."

Strider (2009)

Aidro: "It was the middle section of the project where we weren't sure what their (kinesiology student) role was and they didn't seem sure of what their role was in the building (process). We didn't see much that they could help us with."

Sit Ski (2010)

Bradley: "I feel like in the Kinesiology department they have a lot of access to equipment and we could have used a reflector or a force plate to check out how much force. We didn't use it for this project, it wasn't suggested. We didn't use it because it wasn't really offered to us."

Bocci (2011)

Louie: "One of the things that was upsetting at times was that there were so many people we had to correspond with."

Sit Ski (2009)

Robert: "We could have used the Kinesiology students earlier on for the measurements. I think they could have helped us with the research and the actual understanding of the motion we were designing for. Their guidance earlier would have saved us a lot of headaches." 


\section{Kinesiology Student Focus Group}

A focus group was held with kinesiology students in the Spring of 2012. Responses were highly variable and depended greatly on the specific team with which the Kinesiology students were working. Although the discussions have not been fully analyzed, comments are broken down below with regard to gender ( $\mathrm{M}$ for male respondent, $\mathrm{F}$ for female respondent).

1. How have your attitudes towards engineers changed by participating in the projects?

M. I lived with an engineer, and he was socially awkward... this impression changed when I worked with my groups.

F. Dynamic within their own (the engineers) group was not very good. Their organization skills were not very good. Did not have the necessary organizational or social skills needed to get it done.

F. I had two opposite groups - one group constantly argued and was disorganized. They did the whole project in two weeks. They would explain to me in their own lingo, I didn't understand what was going on. The other group was organized from the get-go. Really good at explaining to me what is going on.

2. What were the most difficult aspects of working on the project?

M. Schedule. Fall was the only time we could meet up. (two comments on this)

M. We didn't get to meet up in person very often.

M. It progressively got worse and worse. It was all email or calling.

M. I got to see them pretty frequently to get updates, but short periods of time.

F. Working with the client was pretty difficult.

F. We met once a week at the same time.

M. Having a client that isn't here makes things difficult. A lot of conference calls.

F. It was hard to communicate with the engineers. I would just sit and watch them do computer mathematics. They would ask me questions sometimes.... My role came more once they started building it.

M. First quarter was good because you could talk to them about disabilities and .... what direction to go .... and help brainstorm. Once product was being built, I didn't know what to do. 
3. What do you think most important attributes that engineers brought to the projects?

M. Actual design... CAD... Figuring out the physics of it.

Several: Technical knowledge. Turn that into ability to make a product.

4. What do you think the engineers could do better to help the success of the project?

F. Maybe give us one-on-one engineering etiquette presentation like we gave them.

F. Is there a way we could do a Solidworks for dummies so we could follow what they are doing?

$\mathrm{M}$ and F: My engineers actually did this for me, explained things to me.

F. Set a time every week to meet.

5. What could you have done better to help success of the project?

M. I kept asking what can I do to help? I can't weld or mill, what am I supposed to do?

M. My involvement became less and less.

In addition, three of the kinesiology students from this past quarter took a survey (based on ref [13]) before they began working on the projects. Although somewhat limited due to the low number, the responses shown in Table 2 provide some insight into the Kinesiology students attitudes towards engineers before starting on the projects.

Table 2. Kinesiology student views on engineering before collaborating with them.

\begin{tabular}{|l|c|c|c|c|c|}
\hline & Str Agr & Agr & Neither & DisAgr & Str Dis \\
\hline Engineers make our lives easier & 2 & 1 & & & \\
\hline $\begin{array}{l}\text { Engineers should listen more to what } \\
\text { ordinary people think }\end{array}$ & & 2 & 1 & & \\
\hline $\begin{array}{l}\text { It is important for people to understand } \\
\text { what engineers contribute to daily life }\end{array}$ & 2 & 1 & & & \\
\hline $\begin{array}{l}\text { Engineering is essential for all human } \\
\text { development }\end{array}$ & & 1 & 1 & 1 & \\
\hline Hardly anyone knows what engineers do & 3 & 2 & 1 & & \\
\hline Engineering is a well-respected profession & & 2 & & 1 & 2 \\
\hline Engineers are very similar to scientists & & 3 & & & \\
\hline $\begin{array}{l}\text { On the whole men make better engineers } \\
\text { than women }\end{array}$ & & 1 & & \\
\hline Engineers fix things & & & & \\
\hline $\begin{array}{l}\text { Engineering makes a good contribution to } \\
\text { society }\end{array}$ & 2 & & & \\
\hline
\end{tabular}


When the Kinesiology students were asked "What is the first word which comes to mind when I say engineer?", they said contractor, designer, and studious. When asked "What is the first word which comes to mind when I say engineering?", they answered building, structure, and design. Finally, they were asked "What expectations do you have about working with engineering students on an adapted physical activity design project?" Answers included:

I expect to see creative solutions.

I expect to work together as much as possible and a positive productive experience for all of us to learn from each other as we spend more time on the project.

I expect them to put forth their best effort and to see it not as senior project or something they have to do, but instead something that will be benefiting others.

Discussion and Conclusions

Although the projects have been largely successful, there is still a lot of work to be done to facilitate the collaboration of the engineering and kinesiology students. In the past, we have generally expected the students to define their own roles and work through different teaming issues. This is the strategy we have taken within the engineering design teams - it has not worked as well for defining the roles of the kinesiology students. The disability etiquette presentations at the beginning of the quarter have been a strong component of the collaboration the engineering students learn a lot, and the kinesiology students have a clearly defined task. Similarly, some of the initial brainstorming and background collaborations have been fruitful.

The roles of the kinesiology students become less clear as the project progresses. They often become client liaisons, and may feel isolated from the design aspects of the project. During the engineering analysis and actual build phases, there is very little for them to do. If these roles are made clear to them at the outset, then we may be able to avoid some of the difficult aspects of the collaboration.

Overall, the students seem to appreciate the opportunity to work with students from other majors. They appreciate the skillset that the different students bring to the team, and hopefully the project are better because of this interaction. To highlight this, one student commented:

Wii B Fit (2009)

Kevin: "I think it's been cool to participate in inter-disciplinary project like this. It gives you a feel for what real-life engineering is like. It's not just CPE's working by them. It's people with different skills and different gifts working in certain places."

Acknowledgments: Funding for this project was provided by the National Science Foundation: "Access by Design: Capstone Projects to Promote Adapted Physical Activity" \#0756210 and "Effects of Adapted Physical Activity Design Projects on Attitudes and Learning", \#1062297. 


\section{References}

1. Centers for Disease Control (2005) Disability and Health in 2005: Promoting the Health and Well-being of People with Disabilities. Retrieved on January 20th, 2007; http://www.cdc.gov/ncbddd/factsheets/Disability_Health_AtAGlance.pdf

2. Comstock, E. M. and Duane, W. M., (1996) "Embed User Values in System Architecture: The Declaration of System Usability". Proc. of the ACM CHI 96 Human Factors in Computing Systems Conference. April 14-18, Vancouver, Canada. pp.420-427.

3. Goodwin, D., Thurmeier, R., \& Gustafson, P. (2004). Reactions to the metaphors of disability: The mediating effects of physical activity. Adapted Physical Activity Quarterly, 21(4).

4. Hey, D.W., McCarey, B.J., Slivovsky, L.A., Taylor, J.K., Self, B.P. and Widmann, J. (2011) Capstone Experiences: Effects of adapted physical activity design projects on attitudes and learning. Frontiers in Education Annual Meeting.

5. Klapwijk, A. (1987). The multiple benefits of sports for the disabled. International Disability Studies, 9(2), 8789.

6. Sherrill, C. \& Tripp, A. (2004) Adapted Physical Activity, Recreation and Sport (6th Edition). New York, NY; McGraw-Hill. pp 218-260.

7. Sim, J. "Collecting and analyzing qualitative data: issues raised by the focus group," Journal of Advanced Nursing, vol. 28, no. 2, 1998, pp. 345-352.

8. Patton M. Qualitative Research and Evaluation Methods, 3rd edition. Newbury Park: Sage. (2002).

9. Pugh, S. (1991) Total Design: Integrated Methods for Successful Product Engineering, Addison-Wesley.

10. Slivovsky, L., Widmann, J., Self, B.P., Taylor, J.K. Hey, D. (2012) Why the Human Connections Formed through Service-learning Matter. American Society for Engineering Education Annual Conference and Exposition.

11. Slivovsky, L., Widmann, J., Self, B.P., and Taylor, J.K. (2011) Integrating Adapted Physical Activity Projects into a Computer Engineering Capstone Class. American Society for Engineering Education Annual Conference and Exposition.

12. Widmann, J., Slivovsky, L.A., Self, B.P., and Taylor, J. K. (2009) Aligning Goals of Capstone Design, Service Learning and Adapted Physical Activity. American Society for Engineering Education Annual Conference and Exposition.

13. Marshall, H. Lynne McClymont, L. and Lucy Joyce, (2007) Public Attitudes to and Perceptions of Engineering and Engineers 2007: A study commissioned by The Royal Academy of Engineering and the Engineering and Technology Board. BMRB/LJ/4545106198. 